\title{
Effect of Sintering Mechanisms On The Mechanical Behaviour of SiC And Kaoline Reinforced Hybrid Aluminium Metal Matrix Composite Fabricated Through Powder Metallurgy Technique
}

\author{
V.S.S Venkatesh \\ NIT Silchar: National Institute of Technology Silchar \\ Ashish B Deoghare ( $\square$ abdeoghare@mech.nits.ac.in ) \\ National Institute of Technology Silchar
}

\section{Research Article}

Keywords: Kaoline reinforcement, Powder metallurgy, Spark Plasma Sintering, Conventional sintering, Microwave Sintering

Posted Date: May 28th, 2021

DOI: https://doi.org/10.21203/rs.3.rs-507949/v1

License: (c) (1) This work is licensed under a Creative Commons Attribution 4.0 International License.

Read Full License 


\section{Abstract}

Hybrid metal matrix composites with naturally available and low-cost reinforcements made tremendous demand in the automobile industry to fabricate parts like Pistons, Automobile body and brake discs because of the superior properties of HMMC compared to monolithic Aluminium. Present work focusses on the fabrication of $\mathrm{Al}-10 \% \mathrm{SiC}-4 \%$ Kaoline HMMC by using conventional sintering, Microwave sintering and Spark Plasma Sintering (SPS) techniques. To reveal the phase identification and the distribution of reinforcements, Fabricated composites were investigated by using XRD, SEM integrated with an EDS analyser. Tensile, Compression and hardness tests were performed as per ASTM standards to study the effect of sintering mechanisms on the fabricated HMMC specimens. Results reveal that an enhancement of 13.3 \% in U.T.S and 11.7 \% Compression strength was observed in the Spark Plasma Sintered HMMC when compared to conventional sintered composite specimens because of lesser sintering temperature, time and the absence of intermetallic compounds in the Spark Plasma Sintering process. The formation of the $\mathrm{Al}_{2} \mathrm{Cu}$ intermetallic compound was identified in the XRD pattern of conventionally sintered $\mathrm{Al}-10 \%$ $\mathrm{SiC}-4 \%$ Kaoline HMMC sample due to the high sintering time and temperature which leads to inadequate mechanical properties. The fractured surface of tensile specimens reveals the presence of cleavages on the conventionally sintered HMMC which conforms the brittle fracture, and the existence of dimples on the Microwave sintered and Spark Plasma Sintered samples which signify that the ductile mode of failure in HMMC samples. Out of the three sintering techniques, Spark Plasma Sintering exhibits superior mechanical properties and lesser porosity levels.

\section{Introduction}

Aluminium based metal matrix composites are predominantly used in defence and automobile industries due to the superior properties such as high corrosion resistance, high strength to weight ratio, and lesser cost $[1,2]$. The strength of the aluminium matrix can be improved by incorporating the harder ceramic reinforcements such as $\mathrm{Al}_{2} \mathrm{O}_{3}, \mathrm{SiC}, \mathrm{B}_{4} \mathrm{C}, \mathrm{TiO}_{2}$ and $\mathrm{ZrC}$ etc.,[3-5]. There are different fabrication processes available for fabricating composite materials like stir casting, compocasting, spray forming, powder metallurgy and in-situ fabrication techniques [6]. Out of all fabrication processes, the powder metallurgy technique was frequently used due to the lesser defects, lesser chance of formation of agglomerations and possibility to fabricate composites nearly net shape in powder metallurgy technique $[1,7,8]$. In powder metallurgy technique, sintering of cold compacts was carried by conventional sintering, Spark Plasma Sintering (SPS) and Microwave sintering processes $[9,10]$. In the case of conventional sintering process, the availability of higher sintering temperature and time creates chemical interactions between the matrix and reinforcements that leads to the formation of agglomerations which reduces the mechanical strength of the composite [11,12]. This limitation in the conventional sintering process can be overcome by adopting advanced sintering processes like Spark Plasma Sintering and Microwave sintering. In the Spark Plasma Sintering technique, the composite specimen is undergone sintering as a result of simultaneous application of pressure and high-temperature plasma created at the interfaces of composite powder particles. The impurities present on the surface of the matrix and reinforcement 
particles were cleaned and the interfaces are activated to establish the strong bonding between the powder particles [13]. With the presence of lesser sintering time in the SPS process, the formation of intermetallic compounds was minimised and the composite samples with lesser porosities and better mechanical properties were fabricated by using the SPS technique [14]. In addition to this, the composites fabricated through Spark Plasma Sintering achieve high density and retain fine microstructure due to the reduced sintering time and temperature [15]. In microwave sintering, heat generated in the powder particles due to the absorption of microwaves and oscillation of powder particles was created at the frequency of the microwave frequencies $[3,16]$. The presence of higher heating rates, energy efficiency and process simplicity makes the microwave sintering process better utilization in industrial applications to sinter ceramic powders [17]. N.Saheb et al., [18] fabricated Al-Mg-Zr composite through Spark Plasma Sintering process and concluded that Al-5 Mg- $\mathrm{Zr}$ composite sintered at $620^{\circ} \mathrm{C}$ achieved higher hardness when compared to Al-10 Mg-5 Zr composite. Nouari sahib et al.,[15] studied the mechanical behaviour of Al6061 and Al2124 synthesised by Spark Plasma Sintering and Microwave sintering. Results concluded that the hardness values increase with the increase in sintering temperature from $400^{\circ} \mathrm{C}$ to $500^{\circ} \mathrm{C}$ and the maximum value of hardness obtained was $70.16 \mathrm{VHN}$ and 117.10 VHN for Spark plasma sintered Al6061 and Al2124 specimens. Based on the above literature, limited work was carried on the Spark Plasma Sintering and Microwave sintering techniques.

Kaoline clay was naturally available, low-cost material contains $\mathrm{Al}_{2} \mathrm{O}_{3}, \mathrm{SiO}_{2}, \mathrm{~K}_{2} \mathrm{O}, \mathrm{Fe}_{2} \mathrm{O}_{3}, \mathrm{MgO}, \mathrm{CaO}$ and $\mathrm{N}_{2} \mathrm{O}$ which improves the mechanical properties of the composite material [19]. The presence of $\mathrm{CaO}$ in the kaoline reacts with $\mathrm{Al}_{2} \mathrm{O}_{3}, \mathrm{SiO}_{2}$ and forms aluminates and silicates which enhances the bonding strength between the adjacent particles and helps to better load transfer from softer aluminium to reinforcement particles [20].

Hence, In this present work, an attempt has been made to fabricate the hybrid aluminium matrix composite by incorporating $\mathrm{SiC}$ as one reinforcement and naturally available Kaoline Clay as secondary reinforcement. The effect of sintering mechanisms (Conventional sintering, Spark Plasma Sintering, Microwave Sintering) on the mechanical characteristics of Al-SiC-Kaoline was investigated.

\section{Materials And Methods}

\subsection{Raw materials}

To fabricate hybrid composite, Aluminium powder having particle size less than $30 \mu \mathrm{m}$ was used as matrix material. SiC particles having a size less than $30 \mu \mathrm{m}$ used as primary reinforcement because of their higher hardness $(280 \mathrm{BHN})$, high melting point $\left(2730^{\circ} \mathrm{C}\right)$ and compression strength $(3900 \mathrm{MPa})$. Kaoline clay having a particle size less than $30 \mu \mathrm{m}$ used as secondary reinforcement in this present study. The particle sizes of SiC and Kaoline is shown in Fig. 1(a,b). The presence of oxides of Silicon, Aluminium, Magnesium makes kaoline as a hard and brittle material [19]. The elements present in kaoline clay is shown in Table 1. The as-received powders were analyzed via XRD to confirm the SiC and Kaoline peaks as shown in Fig. 3. 
Table 1

Elements present in the kaoline clay.

\begin{tabular}{|llllllllll|}
\hline Elements & $\mathrm{Al}_{2} \mathrm{O}_{3}$ & $\mathrm{SiO}_{2}$ & $\mathrm{Fe}_{2} \mathrm{O}_{3}$ & $\mathrm{TiO}_{2}$ & $\mathrm{CaO}$ & $\mathrm{MgO}$ & $\mathrm{K}_{2} \mathrm{O}$ & $\mathrm{NaO}_{2}$ & L.O.I \\
\hline $\mathrm{Wt} \%$ & 38.4 & 45.6 & 0.4 & 1.5 & 0.06 & 0.05 & 0.18 & 0.03 & 13.8 \\
\hline
\end{tabular}

\subsection{Ball milling}

A measured quantity of Aluminium matrix and reinforcement powders are loaded in a chromium steel vial with powder to ball ratio of $1: 10$. Stearic acid was used as a process control agent to avoid the excess cold welding between the matrix and reinforcement powders and prevent the welding between the tungsten balls and powders. The chromium steel vial was sealed with Ar gas to avoid the oxidation of aluminium powder. Ball milling was performed in RESTECH 100 planetary ball mill to distribute the reinforcements uniformly throughout the matrix and to initiate the strain hardening in the powder particles $[1,2,21]$. The parameters adopted for an adequate ball milling process was shown in Table 2 [22].

\subsection{Cold compaction and sintering}

The milled powders were subjected to a compaction process by using a manual pallet press with an application of $600 \mathrm{MPa}$ pressure [23]. $\mathrm{H}-13$ steel dies with rectangular and circular crosssection were used to prepare composite samples for tensile and compression strength. The mixture of Zinc Stearate and acetone was applied to the contact surfaces of punch and die as a lubricant to eject the green compacted composite specimens. To study the mechanical properties of fabricated composite specimens, green compacts were subjected to three different sintering process such as (1) conventional sintering at $620^{\circ} \mathrm{C}$ for $3 \mathrm{~h} \mathrm{(2)} \mathrm{Microwave} \mathrm{sintering} \mathrm{at} 500^{\circ} \mathrm{C}$ for $30 \mathrm{~min}$ [13]. (3) Spark Plasma Sintering in a graphite die at $500^{\circ} \mathrm{C}$ for $5 \mathrm{~min}$ with simultaneous application of $10 \mathrm{MPa}$ and heat rate of $50^{\circ} \mathrm{C} / \mathrm{min}$ (see Fig. 10) [16].

Table 2

Process Parameters for ball milling

\begin{tabular}{|ll|}
\hline Ball material & Tungsten Carbide \\
\hline Vial material & Chromium hardened steel \\
\hline Milling time & $4 \mathrm{~h}$ \\
\hline Milling Speed & $300 \mathrm{rpm}$ \\
\hline Ball to powder ratio & $10: 1$ \\
\hline Process Control Agent (PCA) & Stearic acid \\
\hline
\end{tabular}

\subsection{Characterization of composite samples}

Fabricated composite specimens were subjected to compression test as per ASTM E9 standards on micro universal testing machine M30 model. Tensile test was performed as per ASTM E8 standards having specimen gauge length of $25 \mathrm{~mm}$ with crosshead movement of $0.5 \mathrm{~mm} / \mathrm{min}$. The fabricated 
composite specimens for compression, Hardness and Tensile test is depicted in Fig. $2(a, b)$. The prepared composite specimens were subjected to impact test according to ASTM A370 having a notch area of 100 $\mathrm{mm}^{2}$ [24]. Microhardness of composite samples was measured on ECONOMET VH1MD Vickers hardness tester as per ASTM E384-16 standards [25]. The average of five readings was considered for each sample for better accuracy of the result. To reveal the distribution of reinforcements in the matrix material, fabricated composite samples subjected to W-SEM equipped with an EDS analyser. Prior to W-SEM, To visualize the grain boundaries the specimens were etched by using Kellar's reagent (Mixture of Hydrofluoric Acid (2 ml), Hydrochloric Acid (3 ml), Nitric Acid (2 ml) and Distilled water (190 ml)).

\section{Results And Discussion}

\subsection{Microstructural Characterization}

The fabricated composite specimen corresponding to maximum mechanical strength ( Al- $10 \%$ SiC- $4 \%$ Kaoline) was subjected to W-SEM analysis integrated with an EDS analyser. Results reveal that the conventionally sintered HMMC shows the existence of pores as shown in Fig. 5 (a). In addition to this, the formation of agglomerations along the grain boundaries was observed in the conventionally sintered composite specimen as shown in Fig. 6 . These agglomerations or clusters were formed due to the existence of a large density difference between the matrix and reinforcement particles which leads to a decrease in the mechanical strength of the material. The mechanical strength of the material depends on the interfacial bonding strength between the matrix and reinforcement particles. The agglomerations and pores which were found in the conventional sintering process occupied the interface region of matrix and reinforcement and acts as barriers for the interface bonding between the matrix and reinforcement particles. These agglomerations also act as pre-existing micro-cracks that reduce the load transfer mechanism leads to early failure of composite material.

In the case of Microwave and Spark Plasma Sintered composites, SEM analysis revealed that the absence of porosities and the strong interfacial bond between the matrix and reinforcement particles (see Fig. $5(b, c))$. In addition to this, no agglomerations of particles were observed in the Microwave and Spark Plasma Sintered composites due to the faster heating rate and shorter sintering time which decelerates the chemical interactions between the matrix and reinforcement particles. EDS mapping of microwave and Spark Plasma Sintered composite shows the presence and uniform distribution of silicon (Si), Carbon (C), Oxygen (O), Magnesium (Mg), Iron (Fe), Copper (Cu) and Zinc (Zn) elements ( see Fig. 7, 8 ). The existence of these elements confirms the $\mathrm{SiC}$ and $\mathrm{Kaoline}\left(\mathrm{Al}_{2} \mathrm{O}_{3}, \mathrm{SiO}_{2}, \mathrm{Fe}_{2} \mathrm{O}_{3}, \mathrm{CaO} / \mathrm{MgO}\right)$ in the fabricated HMMC specimen.

\subsection{XRD analysis}

Fig 3. represents the XRD peaks for as received $\mathrm{SiC}$ and Kaoline reinforcements, which confirms the existence of $\mathrm{SiC}$ peaks in $\mathrm{SiC}$ reinforcement and the presence of $\mathrm{Al}_{2} \mathrm{O}_{3}, \mathrm{SiO}_{2}, \mathrm{CaO} / \mathrm{MgO}, \mathrm{TiO}_{2}$ peaks in kaoline reinforcement powder. XRD analysis of composite specimens reveals that the presence of $\mathrm{Al}_{2} \mathrm{Cu}$ peak in the conventionally sintered composite specimen (see Fig 4). The obtained peak corresponding to 
$\mathrm{Al}_{2} \mathrm{Cu}$ fairly matches with the peak identified by Gatea et al., [26]. This $\mathrm{Al}_{2} \mathrm{Cu}$ peak in conventional sintering was formed due to the higher sintering temperature and the initiation of chemical interactions between the added reinforcements and matrix particle [27, 28]. However, these intermetallic peaks were not observed in spark plasma sintered and microwave sintered composite specimens. In the case of the conventional sintering process due to the higher exposure time at higher temperatures causes accelerated diffusion, which initiates the chemical reactions between the Al matrix and harder reinforcements. This, in turn, leads to the formation of secondary phase compounds that deteriorate the strength of the composite specimen [29].

\subsection{Mechanical Characterization}

Al-10\% SiC-X\% Kaoline (X = 0, 2, 4, 6, 8) HMMC fabricated through Conventional sintering technique. The fabricated composite specimens were subjected to mechanical testing and the results reveal that the maximum U.T.S of $263 \mathrm{MPa}$, Compession strength of $282 \mathrm{MPa}$ and Hardness value of $147 \mathrm{VHN}$ was obtained at $\mathrm{Al}-10 \% \mathrm{SiC}-4 \%$ Kaoline HMMC specimen and the corresponding values are shown in Table 3. To investigate the effect of the sintering mechanisms on the mechanical properties, $\mathrm{Al}-10 \% \mathrm{SiC}-4 \%$ Kaoline was sintered through three sintering techniques, such as Conventional Sintering, Microwave Sintering and Spark Plasma Sintering technique. Results concluded that the U.T.S and Compression strength of the composite samples which were sintered through the conventional sintering process is $6.84 \%$ and $7.4 \%$ lesser when compared to the HMMC fabricated through Microwave sintering and $13.3 \%$ and $11.7 \%$ lesser when compared to SPS techniques. This was due to the higher sintering time of green compacts in conventional sintering for achieving a good interfacial bond between matrix and reinforcements. But at higher sintering temperatures, the activation energies of matrix and reinforcement particles increases, which lead to interfacial reactions and resulting in the formation of $\mathrm{Al}_{2} \mathrm{Cu}$ brittle intermetallic compounds as shown in Fig. 4. This $\mathrm{Al}_{2} \mathrm{Cu}$ compound occupies the interfacial gap between the matrix and reinforcements and weakens the bonding strength between the adjacent particles. The existence of difference in deformation capabilities of intermetallic compound and reinforcement powders leads to generate triaxial stresses during the application of load. These internal stresses initiate the crack generation, propagation and failure of the composite specimen when the magnitude of these stresses exceeds the yield strength of the composite specimen [30].

In Microwave sintering, the heat is generated from the core part of the ceramic powder particles due to the absorption of microwaves during sintering [22] (see Fig. 9). The developed heat inside the ceramic particles was propagated to the adjacent Aluminium matrix particles. This phenomenon enhances the interfacial bonding between the composite particles and decreases the temperature gradients between the core part and surface of the composite powders $[14,31]$. The lower sintering time and temperature in microwave sintering improve the grain growth and eliminate the chances of formation of intermetallic phases.

The high U.T.S and Compression strength of Spark Plasma Sintered composite were due to the generated plasma between the powder particles which enhances the bonding strength between the adjacent powder particles by breaking the impurities present on the surface of the matrix and reinforcement particles. In 
addition to this, this generated spark plasma generates joul heating with interface particles and electric discharge between the surrounding particles (see Fig. 10. b) [13]. Further, in the SPS process, the formation of brittle clusters was completely avoided due to the accelerated grain growth due to lesser sintering time that reduces the chemical interactions between the softer aluminium matrix and harder ceramic reinforcements [29]. The effect of sintering techniques on the variation of Hardness, U.T.S and Compression Strength of HMMC is depicted in Fig. 11 and Fig. 12 respectively. Results concluded that the U.T.S, compression strength and hardness of composites sintered by microwave sintering and SPS process can be enhanced by $6.84 \%, 7.44 \%, 6.12 \%$ and $13.3 \%, 11.7 \%$ and $16.3 \%$ respectively.

Table 3. Mechanical properties of fabricated Al- SiC-Kaoline HMMC

\begin{tabular}{|llll|}
\hline & U.T.S (MPa) & Compression Strength (MPa) & Hardness (VHN) \\
\hline Al & 150 & 171 & 98 \\
\hline Al- 10\% SiC & 184 & 203 & 111 \\
\hline Al- 10\% SiC-2\% Kaoline & 202 & 248 & 122 \\
\hline Al- 10\% SiC-4\% Kaoline & 263 & 282 & 147 \\
\hline Al- 10\% SiC-6\% Kaoline & 229 & 252 & 137 \\
\hline Al- 10\% SiC-8\% Kaoline & 193 & 221 & 136 \\
\hline
\end{tabular}

\subsection{Effect of Sintering mechanisms on Porosity of the HMMC}

The percentage of voids present in the given specimen is referred as porosity. Porosity present in the material degrades the mechanical properties of the material. Pores generate the weak interfaces between the matrix and reinforcement particles that act as obstacles for the propagation of heat during the sintering. The existence of thermal mismatch between the matrix and reinforcements causes the differences in the deformation capabilities of softer aluminium matrix and harder reinforcements that create the pores at the interface regions. In the case of spark plasma sintering due to the simultaneous application of pressure and heat over a short time period and the presence of vacuum during the SPS process, the likelihood of pore formation was minimized and causes an efficient diffusion process between the particles. During the compaction process, it was observed that the compressibility of hybrid composite powders decreases with an increase in harder ceramic reinforcement particles. At the low compaction pressure rates (i.e., Quasi-static condition) the powder particles are having sufficient time to rearrangement and fill the interfacial gaps and produce the densified green compacted composite specimen. But at dynamic compaction pressure conditions, the powder particles don't have time to rearrangement such that interlocking occurs about their mean positions and undergone plastic deformation during compaction. This causes very few chances to fill the interfacial gaps that cause high porosity in the composite specimens that degrade the mechanical strength of the fabricated samples 
[30]. In this experiment higher porosity levels of $4.5443 \%$ was obtained for conventionally sintered composite. The SPS and microwave sintered composite specimens showed porosity levels of $1.9523 \%$ and 3.1013 \% respectively as shown in Fig. 13 . In the case of the Spark Plasma Sintering technique, porosity negatively affects the sintering process. Porosities present in the composite acts as electrical resistance and causes acute diversion of electric currents at the junctions of Al-SiC- Al particles (see Fig. 10.b), which prone to decreasing joul heating regions and reduces the densification of material [13]. To eradicate this defect, the reinforcement particles must be dispersed uniformly throughout the matrix which can be achieved by an appropriate selection of process parameters during the ball milling process.

\subsection{Impact Energy}

The energy absorbed by the material before fracture is termed impact energy. Figure 14 Indicates that there was an enhancement of 59.3\% and $75.58 \%$ impact energy for microwave and Spark Plasma Sintered HMMC when compared to Conventional sintered HMMC. The lower impact energy of conventional sintered composite was due to the presence of brittle $\mathrm{Al}_{2} \mathrm{Cu}$ intermetallic compound which was formed as a result of chemical interactions between matrix and reinforcement particles [26]. The brittle intermetallics reduces the energy absorption capability of the material [32,33]. In addition to this, the presence of higher porosity levels and microcracks in conventional sintered composites is the key factor for the lesser impact energy of HMMC [34]. In the case of Microwave and Spark Plasma Sintered HMMC's, the presence of shorter sintering time and temperature makes the specimens free from agglomerations and causes a strong interfacial bond which makes the large plastic deformation at highstress concentration areas before the fracture [35]. The high impact energy of Microwave and Spark Plasma Sintered HMMC leads to ductile fracture under the application of load.

\subsection{Fractography}

Fracture in the tensile specimen is classified into the brittle fracture and ductile fracture. The distribution of reinforcement particles in the matrix material, interfacial bonding between the particles and the agglomerations which are formed due to the chemical interactions between the adjacent particles are the essential factors that affect the type of fracture in tensile specimens. The non-uniform dispersion of reinforcements leads to variation in a strain carrying potentiality between the softer aluminium matrix and harder ceramic reinforcements (SiC, Kaoline). The presence of clusters weakens the interfacial bond which promotes the early stage failure of the composite under the application of load.

Fractured tensile specimens are subjected to SEM analysis to know the fractured patterns like Dimple and cleavage facts. The formation of Dimples was generally formed on the fracture surface of the ductile specimen with large plastic deformation and localized stresses [36, 37]. Transgranular cleavages occur on the brittle fracture which enhances the propagation of crack through the intergranular grain boundaries [32, 33, 38, 39]. Figure 15(a-c) represents the SEM micrographs for the tensile fractured surfaces. The presence of harder reinforcements and the formation of $\mathrm{Al}_{2} \mathrm{Cu}$ intermetallic compound due to the large sintering time of conventional sintering promotes cleavage facts on the fractured surface as shown in Fig. 14(a). In the case of microwave and Spark Plasma Sintering, as the composite specimens are sintered in less time brittle agglomerations was not found in XRD patterns of SPS and Microwave 
Sintering. Figure $14(b, c)$ reveals the presence of dimples due to the absence of $\mathrm{Al}_{2} \mathrm{Cu}$ intermetallic compound which causes ductile failure and enhances the elastic nature of composite specimens [40].

\section{Economical Analysis}

Table 4

Cost analysis for Fabricated HMMC specimens(Approximate Cost)

\begin{tabular}{|llllll|}
\hline & $\begin{array}{l}\text { Availability } \\
\text { of } \\
\text { Equipment }\end{array}$ & $\begin{array}{l}\text { No. of samples that } \\
\text { can be sintered at a } \\
\text { time }\end{array}$ & $\begin{array}{l}\text { Sintering cost } \\
\text { per sample } \\
\text { (Rs) }\end{array}$ & $\begin{array}{l}\text { Labour } \\
\text { cost (Rs) }\end{array}$ & $\begin{array}{l}\text { Total cost to } \\
\text { fabricate one } \\
\text { sample (Rs) }\end{array}$ \\
\hline $\begin{array}{l}\text { Conventional } \\
\text { Sintering }\end{array}$ & High & More than one & $>150$ & Less & Nearly 200 \\
$\begin{array}{l}\text { Microwave } \\
\text { Sintering }\end{array}$ & Moderate & More than one & $>1000$ & moderate & Nearly 2500 \\
$\begin{array}{l}\text { Spark } \\
\text { Plasma } \\
\text { Sintering }\end{array}$ & Less & Limited & $>3500$ & High & Nearly 8000 \\
\hline
\end{tabular}

From an economical study, it was clear that the productivity is high for the conventional sintering process when compared to microwave and spark plasma sintering. The conventional sintering process was preferred for the fabrication of components that are Less important in engineering applications. In the case of Microwave sintering, the sintering cost is high compared to conventional sintering as the availability of equipment is less and high power consumption during sintering (see Table 4.) In the Spark plasma sintering process, the high cost of the initial set-up and cost of graphite die makes the SPS process costlier compared to the microwave sintering process. To fabricate the high precision components with lesser defects, these modern sintering techniques ( microwave sintering and spark plasma sintering) are adopted as the lesser sintering time and temperature that can reduce the formation of intermetallic compounds. From an economical point of view, the microwave sintering process can be the best suitable method to fabricate the composite with lesser defects instead SPS technique. SPS technique was generally employed for the materials which are not possible to sinter by using conventional sintering such as Refractory materials, hard materials and metastable phases [41].

\section{Conclusions}

The present investigation explored the fabrication of Al-10\% SiC-4\% Kaoline HMMC through Conventional Sintering, Microwave Sintering and Spark Plasma Sintering processes. The conclusions drawn from this present study were summarized below.

- The high sintering time in conventional sintering leads to the formation of $\mathrm{Al}_{2} \mathrm{Cu}$ agglomerations, which acts as barriers for load transfer from matrix to reinforcements and leads to composite failure at the lower stress levels when compared to composite sintered through Microwave and Plasma Spark Sintering. 
- The presence of lower porosity levels in the Spark Plasma Sintered composite, makes the strong intermetallic bond between the softer aluminium and harder ceramic reinforcements when compared to conventional and microwave sintering process. This phenomenon makes the Plasma Spark Sintered HMMC samples exhibit maximum U.T.S of $298 \mathrm{MPa}$ and Compression Strength of 315 MPa.

- Fractured tensile specimens reveal that the presence of brittle failure due to the presence of brittle $\mathrm{Al}_{2} \mathrm{Cu}$ agglomerations. the presence of lower sintering time in microwave and Plasma Spark Sintering makes composite free from agglomerations and causes ductile failure in Microwave and Plasma Spark Sintered HMMC samples.

- From an economical point of view, the microwave sintering process is the best preferable fabrication process with minimal defects. But for high precision components and sintering of refractory materials and hard ceramics Plasma Spark Sintering process is the best-recommended method to fabricate HMMC specimens.

\section{Abbreviations}

HMMC Hybrid Metal Matrix Composites

U.T.S Ultimate Tensile Strength

Y.S Yield Strength

SEM Scanning Electron Microscopy

EDS Electron Dispersive Microscopy

XRD X-Ray Diffraction

VHN Vickers Hardness Number

SPS Spark Plasma Sintering

\section{Declarations}

Acknowledgements Authors like to thank Central Instrumentation Facility at National Institute of Technology Silchar for XRD analysis. The authors also would like to appreciate the Advance centre for Material Science at Indian Institute of Technology Kanpur for SEM and EDS analysis.

\section{Author's Contribution}

V.S.S Venkatesh carried out the fabrication, Mechanical characterization of composite samples and Drafted the initial version of the manuscript. Ashish B Deoghare Reviewed and Edited the prepared manuscript. All authors read and approved the final manuscript. 


\section{Data Availability}

Authors confirm that the entire data obtained during the Experiment was included in this available manuscript.

Funding Statement Not applicable.

\section{Conflict of interest}

Authors declared that they have no conflict of interest.

Ethical Approval Ethics Approval All experiments were conducted ethically and no issues regarding ethical issues arouse during the experiments or the manuscript confection.

Compliance with Ethical Standards The Authors declare that they don't have known personal relationships or competing financial interest that could have appeared to influence the work reported in this manuscript.

Research Involving Human Participants and/or Animals Not applicable

Informed Consent Not applicable.

\section{Consent to Participate}

All the Authors are happily agree to contribute in this research work.

\section{Consent for Publication}

Consent was obtained from all authors to publish this manuscript. All the authors read and approved this manuscript to publish this article.

\section{References}

1. Manohar G, Dey A, Pandey KM, Maity SR (2018) Fabrication of metal matrix composites by powder metallurgy: A review. AIP Conf Proc 1952:. https://doi.org/10.1063/1.5032003

2. Venkatesh VSS, Deoghare AB (2020) Effect of controllable parameters on the tribological behavior of ceramic particulate reinforced aluminium metal matrix composites: A review. J Phys Conf Ser 1451: https://doi.org/10.1088/1742-6596/1451/1/012025

3. Prashantha Kumar HG, Anthony Xavior M (2018) Encapsulation and microwave hybrid processing of Al 6061-Graphene-SiC composites. Mater Manuf Process 33:19-25.

https://doi.org/10.1080/10426914.2017.1279320

4. Kanthavel K, Sumesh KR, Saravanakumar P (2016) Study of tribological properties on $\mathrm{Al} / \mathrm{Al} 2 \mathrm{O3} / \mathrm{MoS} 2$ hybrid composite processed by powder metallurgy. Alexandria Eng J 55:13-17. https://doi.org/10.1016/j.aej.2016.01.024 
5. Erdemir F, Canakci A, Varol T (2015) Microstructural characterization and mechanical properties of functionally graded Al2024/SiC composites prepared by powder metallurgy techniques. Trans Nonferrous Met Soc China (English Ed 25:3569-3577. https://doi.org/10.1016/S10036326(15)63996-6

6. Samal P, Vundavilli PR, Meher A, Mahapatra MM (2020) Recent progress in aluminum metal matrix composites: A review on processing, mechanical and wear properties. J Manuf Process 59:131-152

7. Venkatesh VSS, Deoghare AB (2020) Fabrication and mechanical behaviour of Al-Kaoline metal matrix composite fabricated through powder metallurgy technique. In: Materials Today: Proceedings. Elsevier Ltd, pp 3291-3296

8. Manohar G, Pandey KM, Maity SR (2020) Effect of china clay on mechanical properties of AA7075/B4C hybrid composite fabricated by powder metallurgy techniques. Mater Today Proc. https://doi.org/10.1016/j.matpr.2020.10.740

9. Mendoza-Duarte JM, Estrada-Guel I, Carreño-Gallardo C, Martínez-Sánchez R (2015) Study of Al composites prepared by high-energy ball milling; Effect of processing conditions. J Alloys Compd 643:S172-S177. https://doi.org/10.1016/j.jallcom.2015.01.018

10. Popov VA, Shelekhov EV, Prosviryakov AS et al (2017) Particulate metal matrix composites development on the basis of in situ synthesis of TiC reinforcing nanoparticles during mechanical alloying. J Alloys Compd 707:365-370. https://doi.org/10.1016/j.jallcom.2016.10.051

11. Li Y, Yang B, Zhang P et al (2021) Cu-Cr-Mg alloy with both high strength and high electrical conductivity manufactured by powder metallurgy process. Mater Today Commun 27:102266. https://doi.org/10.1016/j.mtcomm.2021.102266

12. Zhou Z, Liu B, Guo W et al (2021) Corrosion behavior and mechanism of FeCrNi medium entropy alloy prepared by powder metallurgy. J Alloys Compd 867:159094. https://doi.org/10.1016/j.jallcom.2021.159094

13. Pakdel A, Witecka A, Rydzek G, Awang Shri DN (2017) A comprehensive microstructural analysis of Al-WC micro- and nano-composites prepared by spark plasma sintering. Mater Des 119:225-234. https://doi.org/10.1016/j.matdes.2017.01.064

14. Ağaoğulları D (2019) Effects of ZrC content and mechanical alloying on the microstructural and mechanical properties of hypoeutectic Al-7 wt.\% Si composites prepared by spark plasma sintering. Ceram Int 45:13257-13268. https://doi.org/10.1016/j.ceramint.2019.04.013

15. Saheb N (2013) Spark plasma and microwave sintering of Al6061 and Al2124 alloys. Int J Miner Metall Mater V 20:. https://doi.org/10.1007/s12613-013-0707-6

16. Reddy MP, Shakoor RA, Parande G et al (2017) Enhanced performance of nano-sized SiC reinforced Al metal matrix nanocomposites synthesized through microwave sintering and hot extrusion techniques. Prog Nat Sci Mater Int 27:606-614. https://doi.org/10.1016/j.pnsc.2017.08.015

17. Leonelli C, Veronesi P, Denti L et al (2008) Microwave assisted sintering of green metal parts. J Mater Process Technol 205:489-496. https://doi.org/10.1016/j.jmatprotec.2007.11.263 
18. Saheb N, Hakeem AS, Khalil A et al (2013) Synthesis and spark plasma sintering of Al-Mg-Zr alloys. J Cent South Univ 20:7-14. https://doi.org/10.1007/s11771-013-1452-8

19. Manikandan R, Arjunan TV, Akhil AR (2020) Studies on micro structural characteristics, mechanical and tribological behaviours of boron carbide and cow dung ash reinforced aluminium (Al 7075) hybrid metal matrix composite. Compos Part B Eng 183:107668. https://doi.org/10.1016/j.compositesb.2019.107668

20. Koo SM, Kim KR, Jiang C et al (2015) Properties of CaO-SiO2 nanocomposites prepared on pure magnesium by using a sol-gel dip-coating technique. J Korean Phys Soc 67:1925-1929. https://doi.org/10.3938/jkps.67.1925

21. Ravi Kumar K, Pridhar T, Sree Balaji VS (2018) Mechanical properties and characterization of zirconium oxide (ZrO2) and coconut shell ash(CSA) reinforced aluminium (Al 6082) matrix hybrid composite. J Alloys Compd 765:171-179. https://doi.org/10.1016/j.jallcom.2018.06.177

22. Manohar G, Pandey KM, Maity SR (2021) Effect of sintering mechanisms on mechanical properties of AA7075/B4C composite fabricated by powder metallurgy techniques. Ceram Int. https://doi.org/https://doi.org/10.1016/j.ceramint.2021.02.073

23. Ozkaya S, Canakci A (2016) Effect of the B4C content and the milling time on the synthesis, consolidation and mechanical properties of AlCuMg-B4C nanocomposites synthesized by mechanical milling. Powder Technol 297:8-16. https://doi.org/10.1016/j.powtec.2016.04.004

24. Ramadoss N, Pazhanivel K, Anbuchezhiyan G (2020) Synthesis of B4C and BN reinforced Al7075 hybrid composites using stir casting method. J Mater Res Technol 9:6297-6304. https://doi.org/10.1016/j.jmrt.2020.03.043

25. Toptan F, Kilicarslan A, Karaaslan A et al (2010) Processing and microstructural characterisation of AA 1070 and AA 6063 matrix B4Cp reinforced composites. Mater Des 31:S87-S91. https://doi.org/10.1016/j.matdes.2009.11.064

26. Gatea S, Ou H, McCartney G (2018) Deformation and fracture characteristics of Al6092/SiC/17.5p metal matrix composite sheets due to heat treatments. Mater Charact 142:365-376. https://doi.org/10.1016/j.matchar.2018.05.050

27. Zhang L, Shi G, Xu K et al (2020) Phase transformation and mechanical properties of B4C/Al composites. J Mater Res Technol 9:2116-2126. https://doi.org/10.1016/j.jmrt.2019.12.042

28. Viala JC, Bouix J, Gonzalez G, Esnouf C (1997) Chemical reactivity of aluminium with boron carbide. J Mater Sci 32:4559-4573. https://doi.org/10.1023/A:1018625402103

29. Liu R, Wu C, Zhang J et al (2018) Microstructure and mechanical behaviors of the ultrafine grained AA7075/B4C composites synthesized via one-step consolidation. J Alloys Compd 748:737-744. https://doi.org/10.1016/j.jallcom.2018.03.152

30. Abdollahi A, Alizadeh A, Baharvandi HR (2014) Dry sliding tribological behavior and mechanical properties of Al2024-5wt.\%B4C nanocomposite produced by mechanical milling and hot extrusion. Mater Des 55:471-481. https://doi.org/10.1016/j.matdes.2013.09.024 
31. Ashwath P, Xavior MA (2018) Effect of ceramic reinforcements on microwave sintered metal matrix composites. Mater Manuf Process 33:7-12. https://doi.org/10.1080/10426914.2016.1244851

32. Baradeswaran A, Elayaperumal A, Franklin Issac R (2013) A statistical analysis of optimization of wear behaviour of Al- Al 203 composites using taguchi technique. Procedia Eng 64:973-982

33. Fadavi Boostani A, Tahamtan S, Jiang ZY et al (2015) Enhanced tensile properties of aluminium matrix composites reinforced with graphene encapsulated SiC nanoparticles. Compos Part A Appl Sci Manuf 68:155-163. https://doi.org/10.1016/j.compositesa.2014.10.010

34. Surya MS, Prasanthi G, Gugulothu SK (2021) Investigation of Mechanical and Wear Behaviour of Al7075/SiC Composites Using Response Surface Methodology. Silicon. https://doi.org/10.1007/s12633-020-00854-y

35. Sharma P, Sharma S, Khanduja D (2016) Effect of graphite reinforcement on physical and mechanical properties of aluminum metal matrix composites. Part Sci Technol 34:17-22. https://doi.org/10.1080/02726351.2015.1031924

36. Bhowmik A, Dey D, Biswas A (2020) Comparative Study of Microstructure, Physical and Mechanical Characterization of SiC/TiB2 Reinforced Aluminium Matrix Composite. Silicon. https://doi.org/10.1007/s12633-020-00591-2

37. Manigandan K, Srivatsan TS, Ren Z, Zhao J (2016) Influence of reinforcement content on tensile response and fracture behavior of an aluminum alloy metal matrix composite. Adv Compos Aerospace. Mar L Appl II 2013:103-119. https://doi.org/10.1007/978-3-319-48141-8_8

38. Balasubramanian I, Maheswaran R (2015) Effect of inclusion of SiC particulates on the mechanical resistance behaviour of stir-cast AA6063/SiC composites. Mater Des 65:511-520. https://doi.org/10.1016/j.matdes.2014.09.067

39. Ozden S, Ekici R, Nair F (2007) Investigation of impact behaviour of aluminium based SiC particle reinforced metal-matrix composites. Compos Part A Appl Sci Manuf 38:484-494. https://doi.org/10.1016/j.compositesa.2006.02.026

40. Bhowmik A, Chakraborty D, Dey D, Biswas A (2019) Investigation on wear behaviour of Al7075-SiC metal matrix composites prepared by stir casting. In: Materials Today: Proceedings. Elsevier Ltd, pp 2992-2995

41. Anselmi-Tamburini U (2019) Spark Plasma Sintering. In: Reference Module in Materials Science and Materials Engineering. Elsevier

\section{Figures}



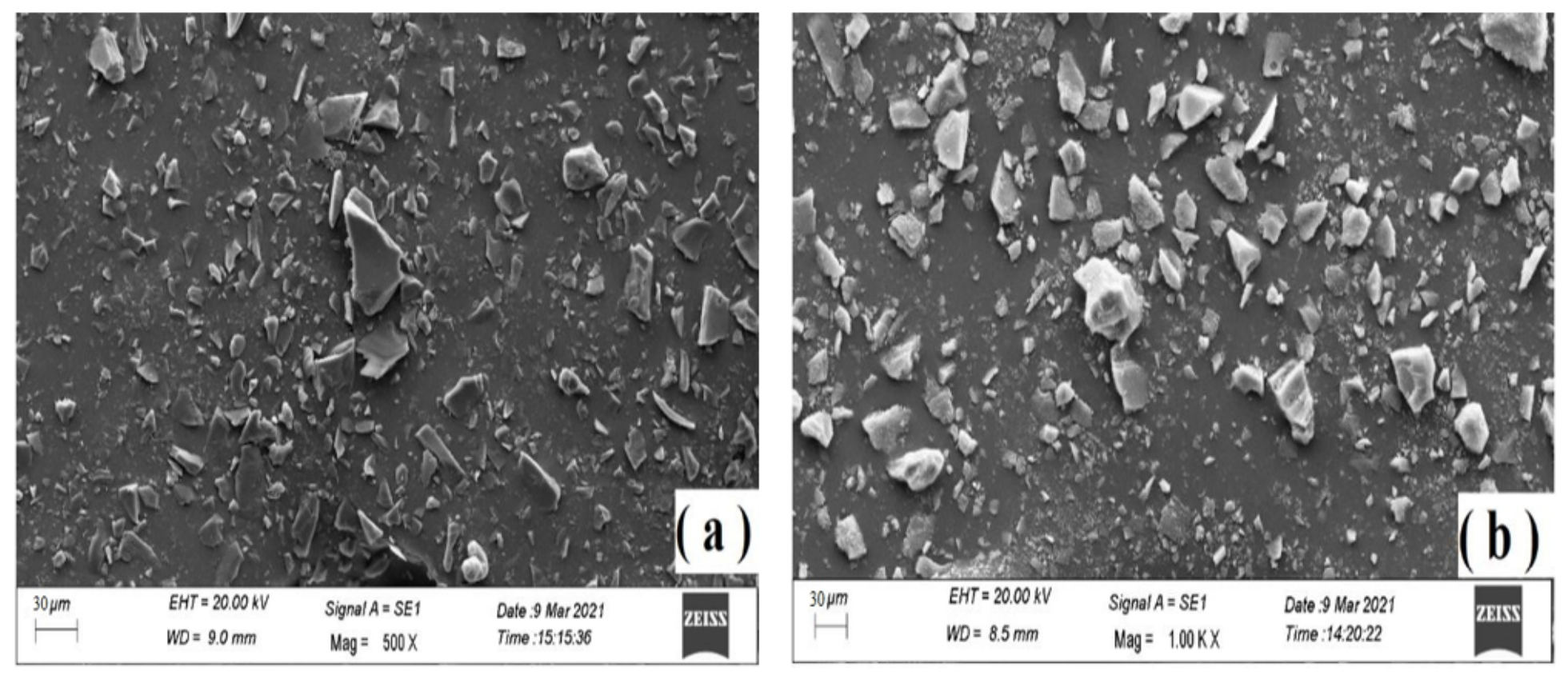

\section{Figure 1}

Particle sizes of (a) SiC reinforcement,(b) Kaoline reinforcement
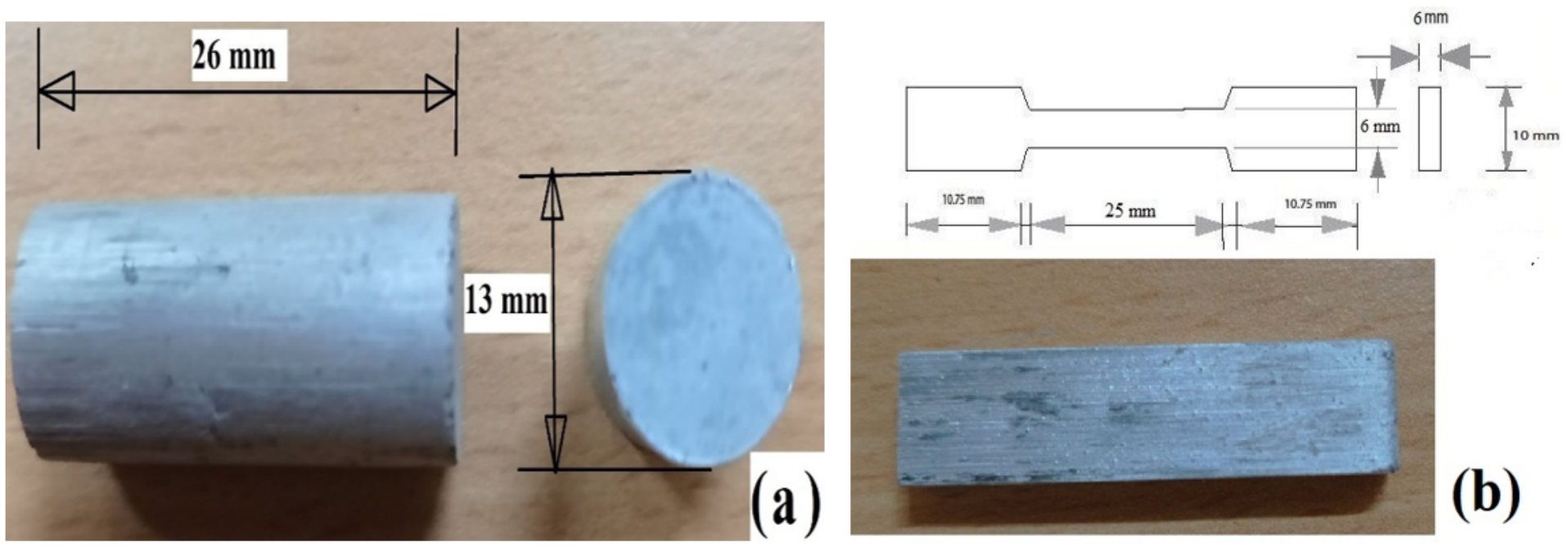

Figure 2

Fabricated samples for (a) Compression and Hardness test, (b) Tensile test 


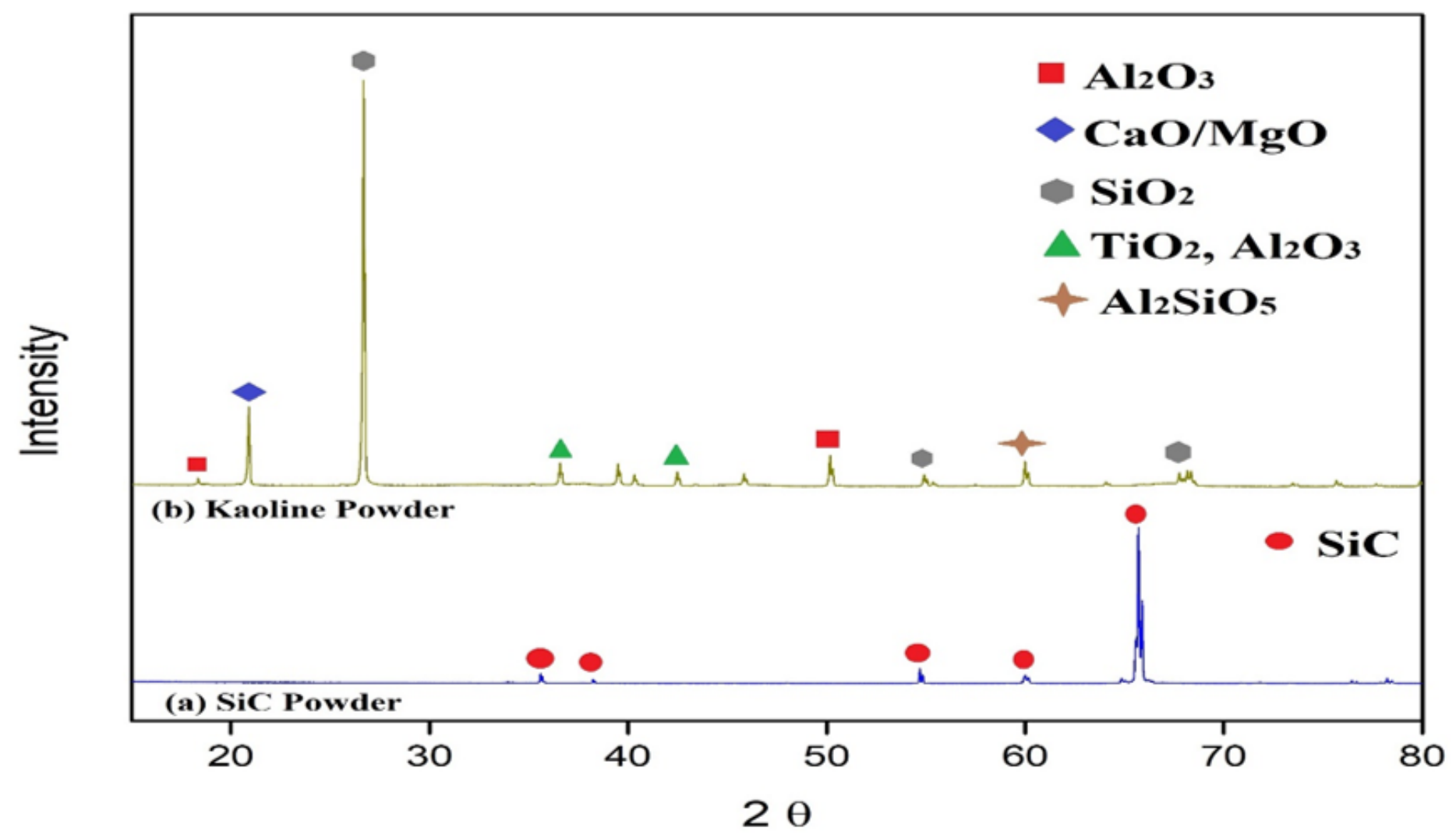

Figure 3

XRD patterns of As received (a) SiC powder, (b) Kaoline powder

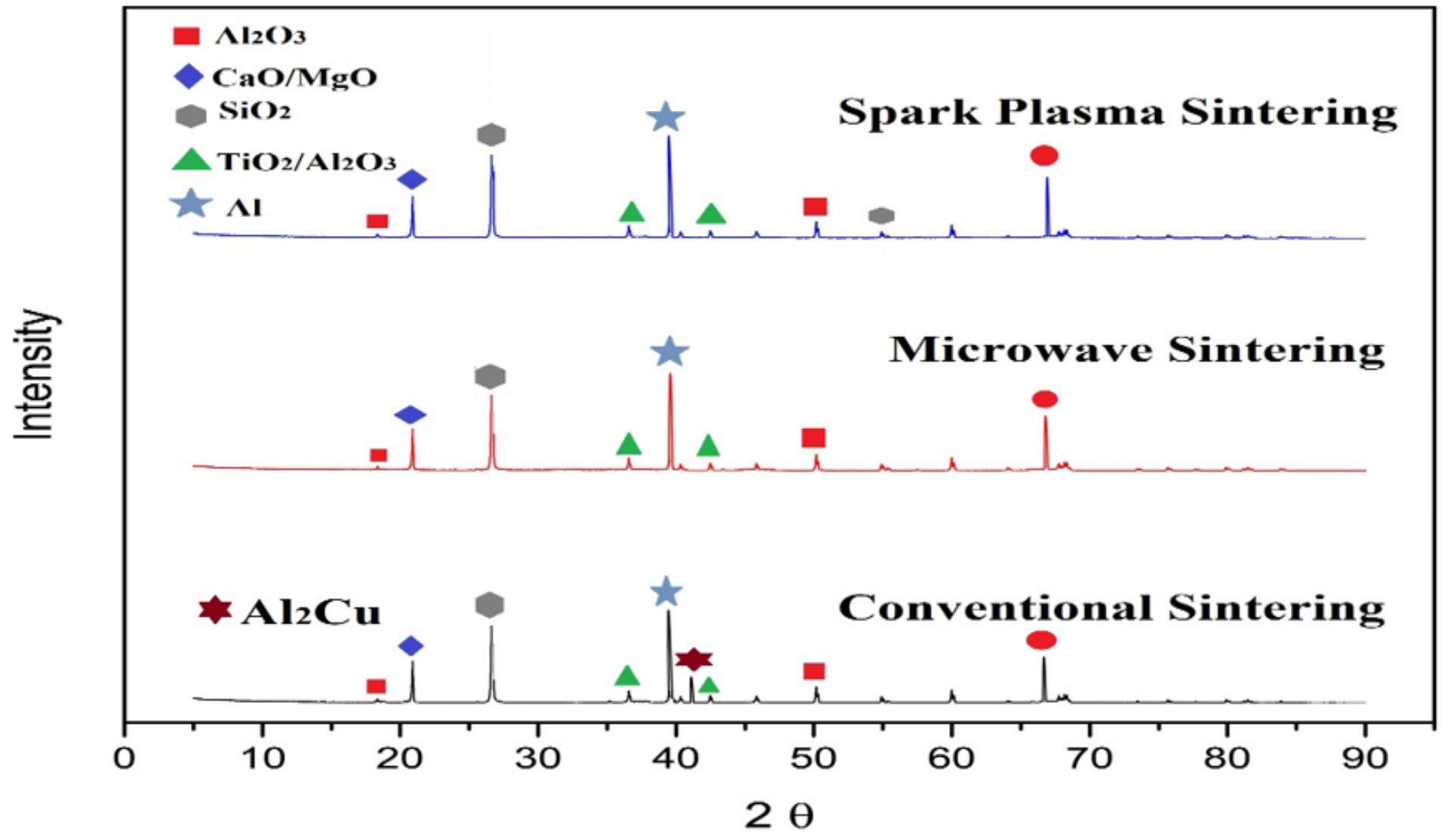


Figure 4

XRD patterns of the fabricated composite specimens
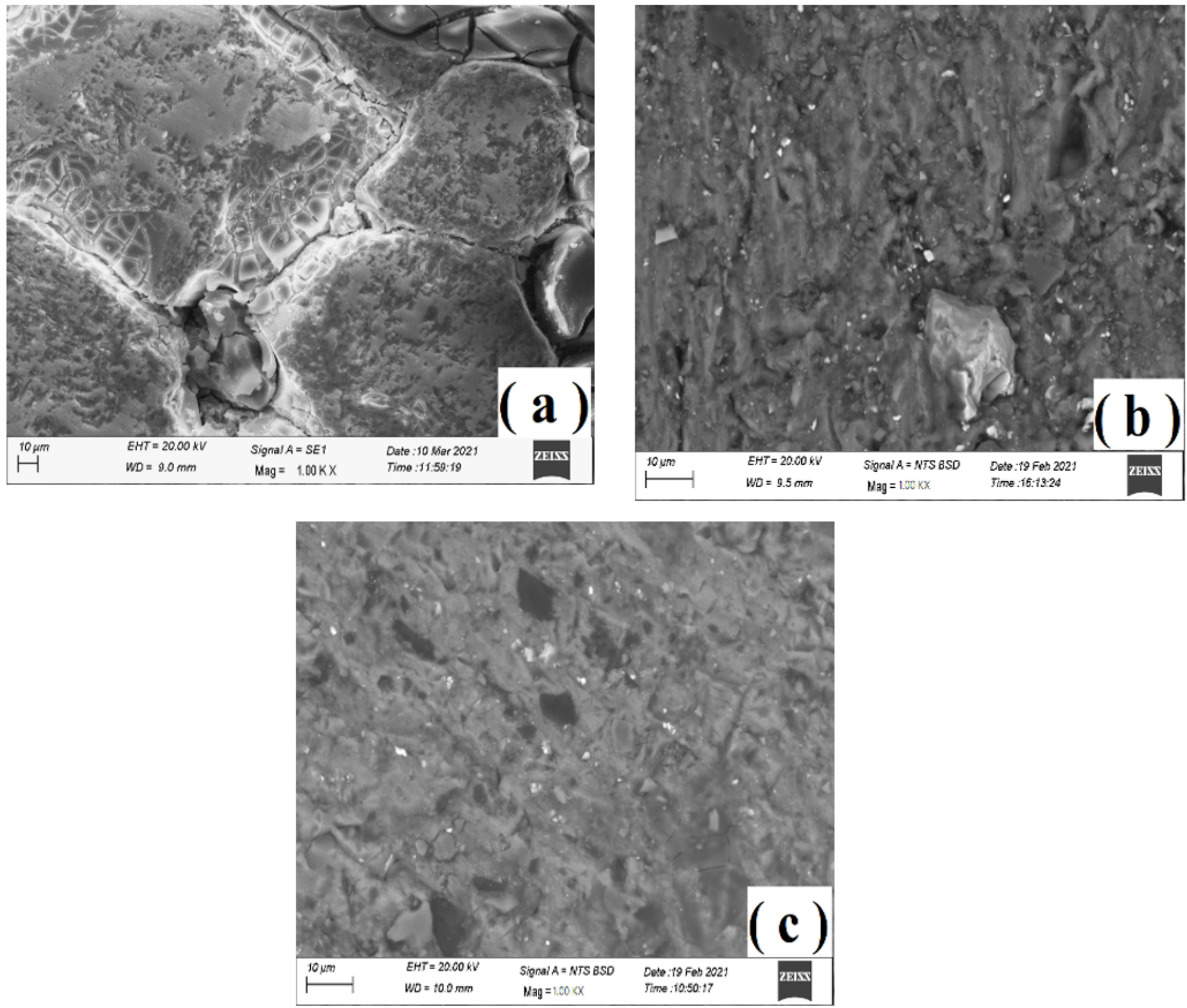

\section{Figure 5}

SEM micrographs of composite specimens sintered by (a) Conventional Sintering, (b) Microwave Sintering, (c) Spark Plasma Sintering 


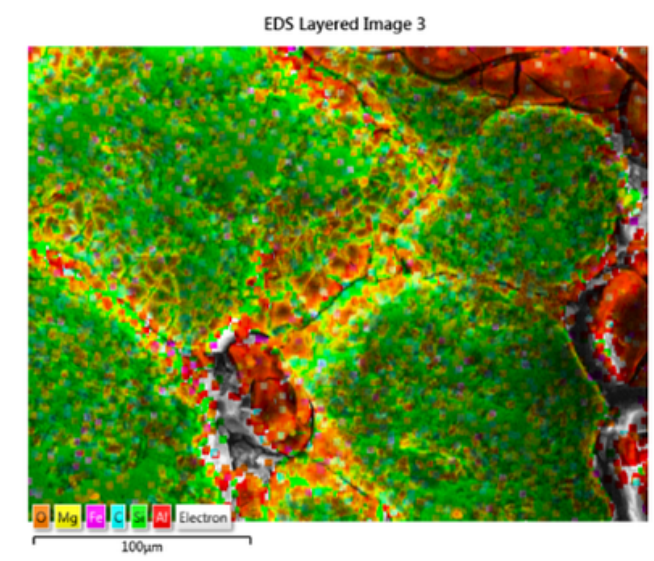

\section{$\mathrm{O} K \alpha 1$}

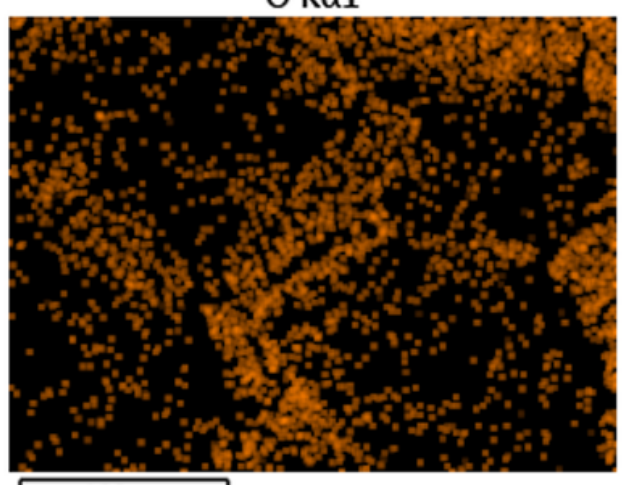

$100 \mu \mathrm{m}$
Si $K \alpha 1$

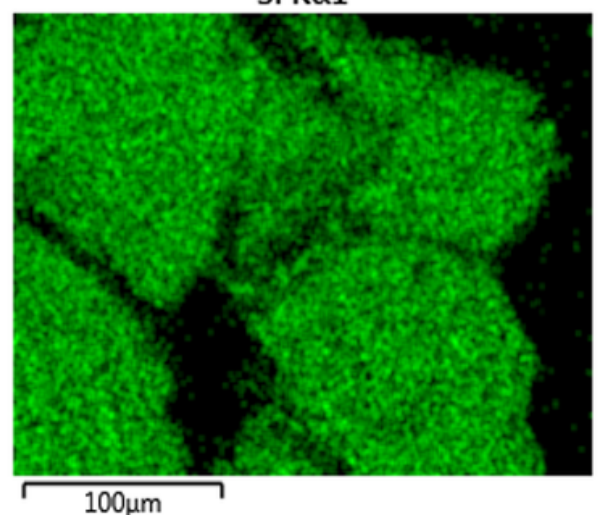

C Ka1_2

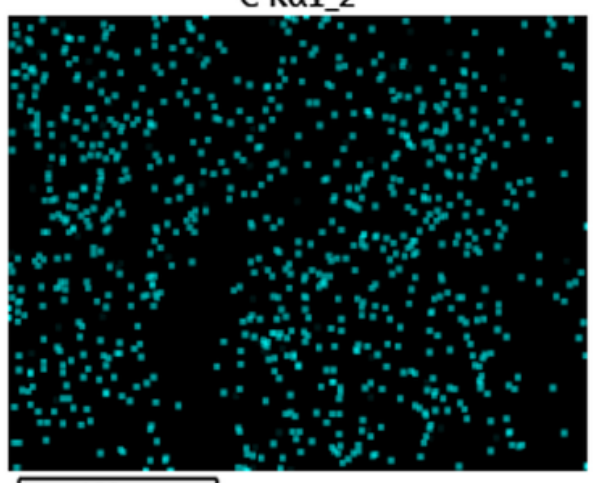

$100 \mu \mathrm{m}$

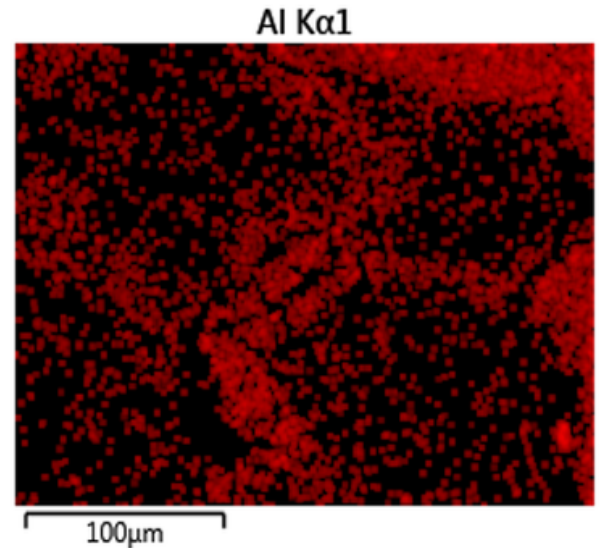

Mg Ka1_2

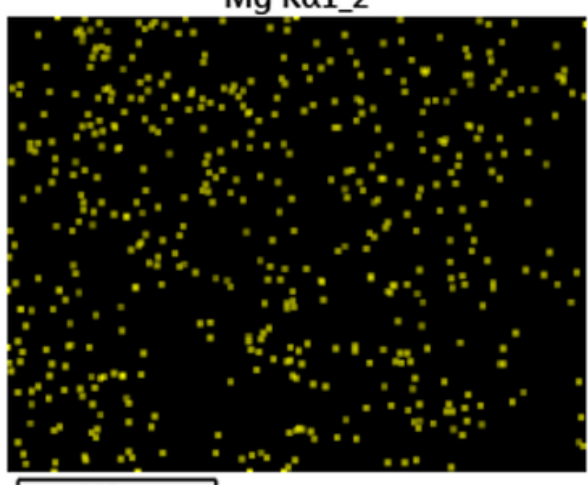

$100 \mu \mathrm{m}$

\section{Figure 6}

Energy Dispersive Spectroscopy (EDS) images for Conventional Sintered Composite 
EDS Layered Image 9

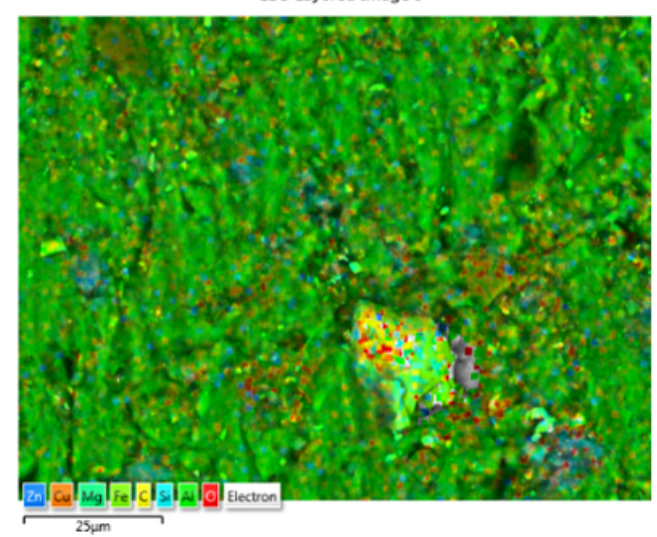

C Ka1_2

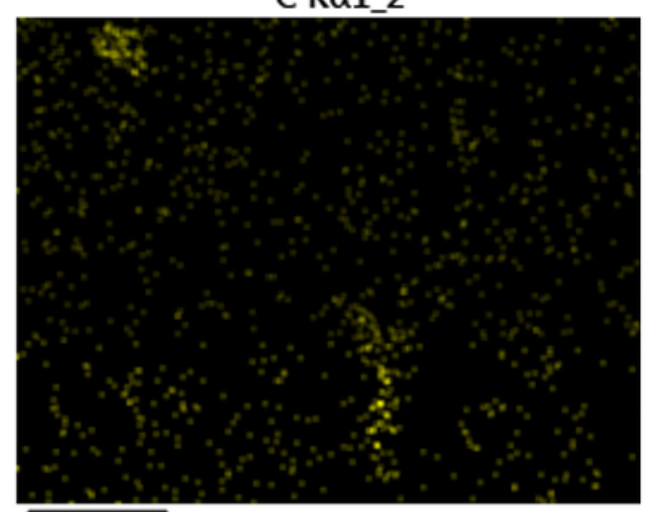

$25 \mu \mathrm{m}$

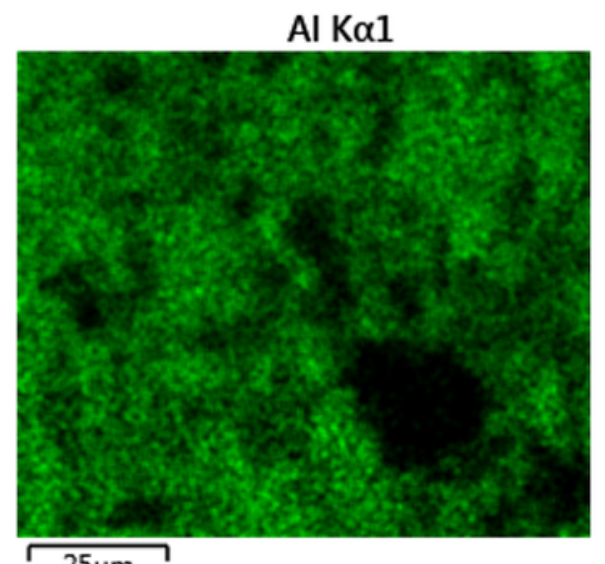

$25 \mu \mathrm{m}$

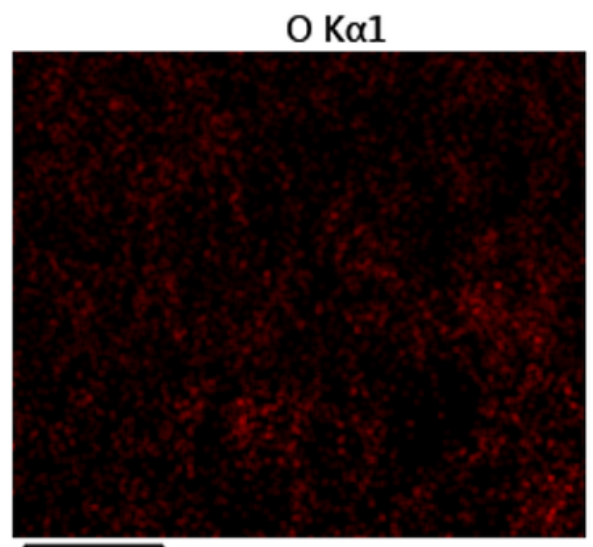

$25 \mu \mathrm{m}$
Si $K \alpha 1$

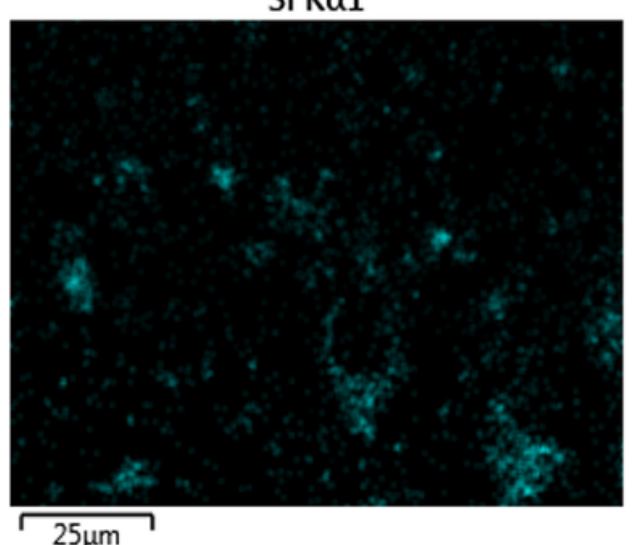

$\mathrm{Mg} \mathrm{K \alpha 1 \_ 2}$

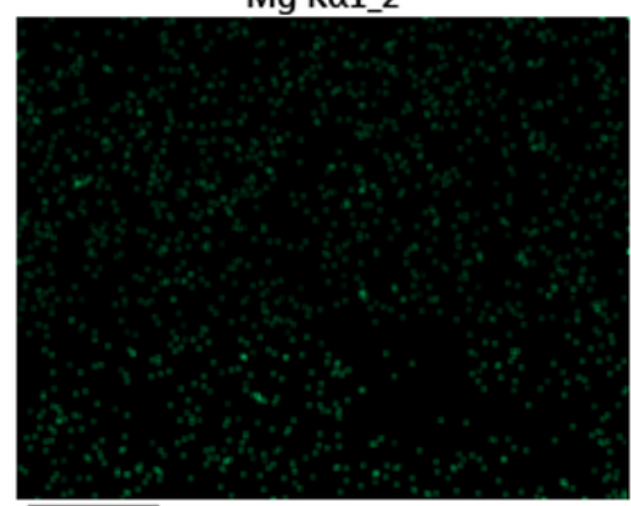

$25 \mu \mathrm{m}$

\section{Figure 7}

Energy Dispersive Spectroscopy (EDS) images for Microwave sintered Composite 
EDS Layered Image 2

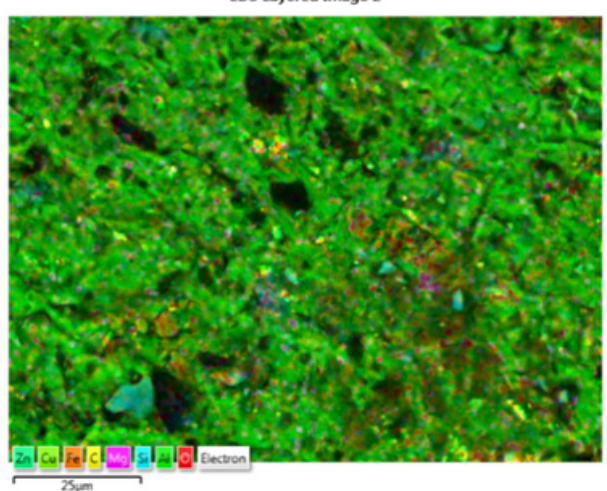

C Ka1_2

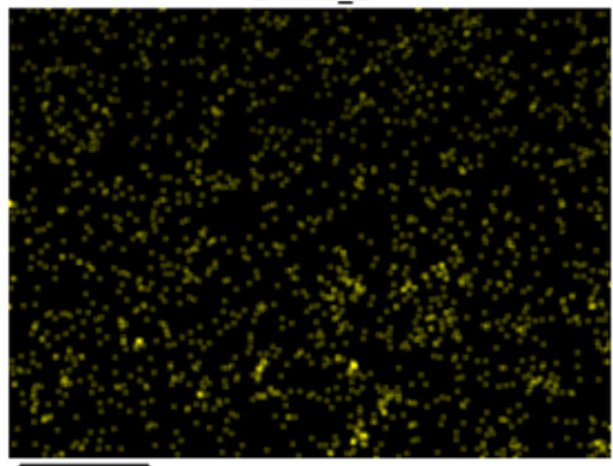

$\longdiv { 2 5 \mu \mathrm { m } }$

Fe K $\alpha 1$

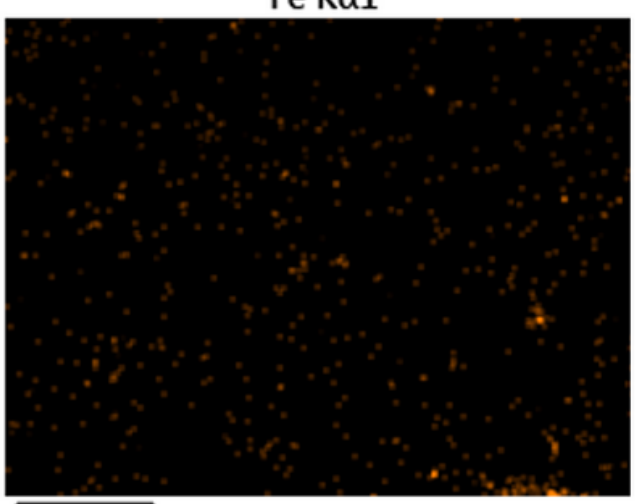

$25 \mu \mathrm{m}$
Al Ka1

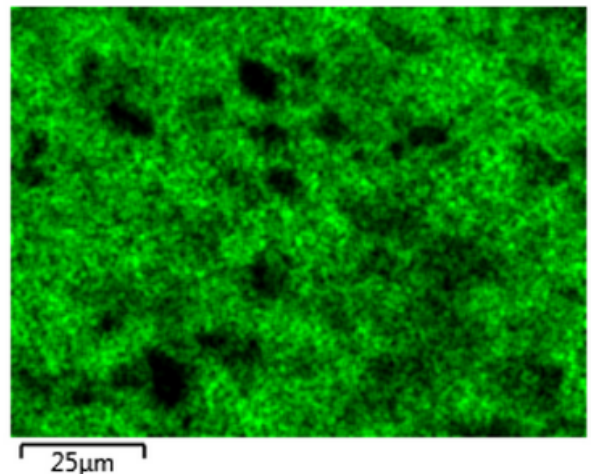

$\mathrm{O} K \alpha 1$

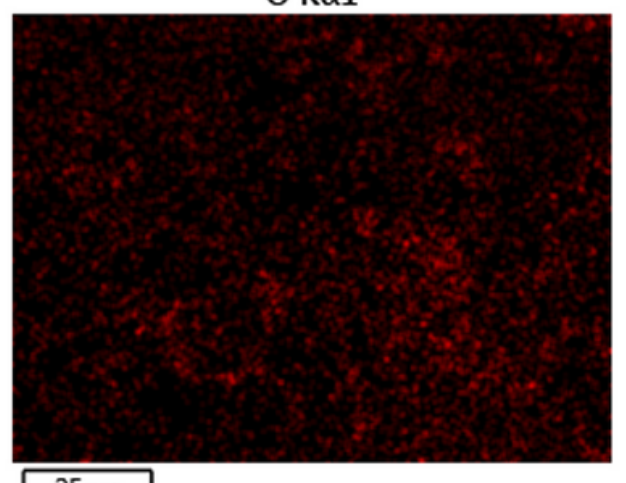

$\longdiv { 2 5 \mu \mathrm { m } }$

$\mathrm{Cu} \mathrm{K \alpha 1}$

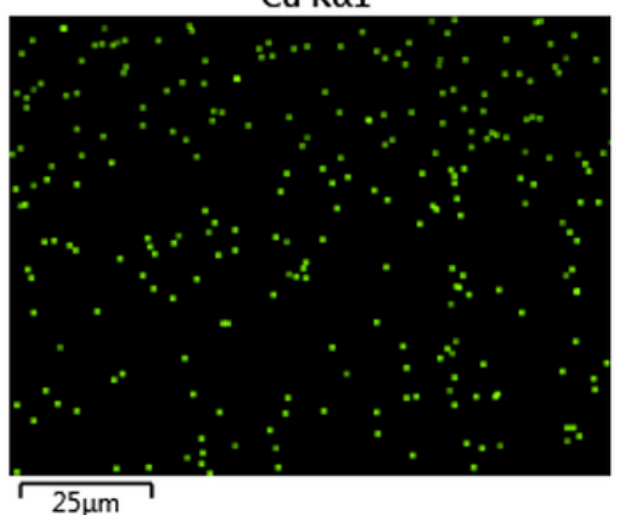

Si $K \alpha 1$

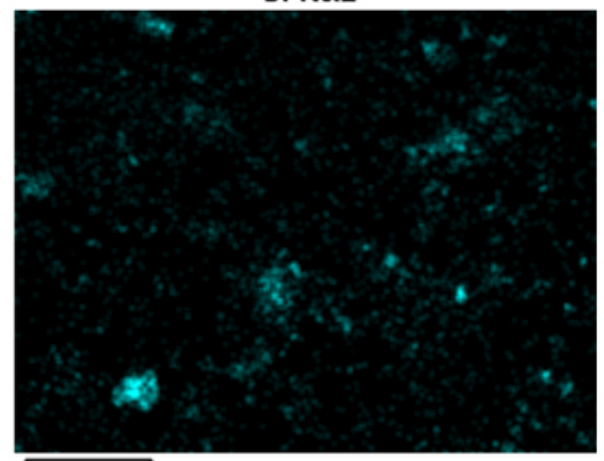

$\mathrm{Mg} \mathrm{K} \alpha 1 \_2$

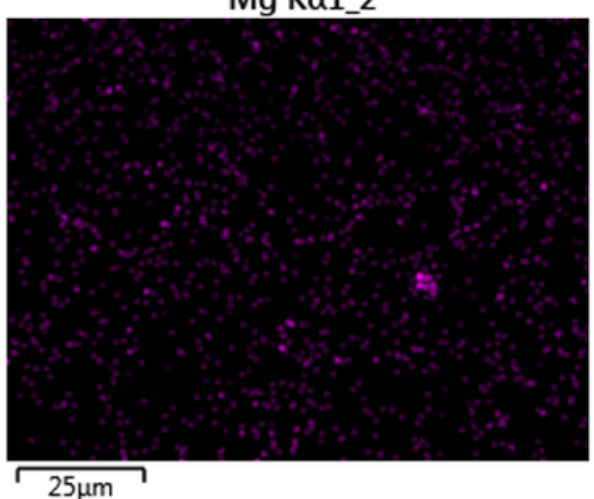

Zn K $\alpha 1$

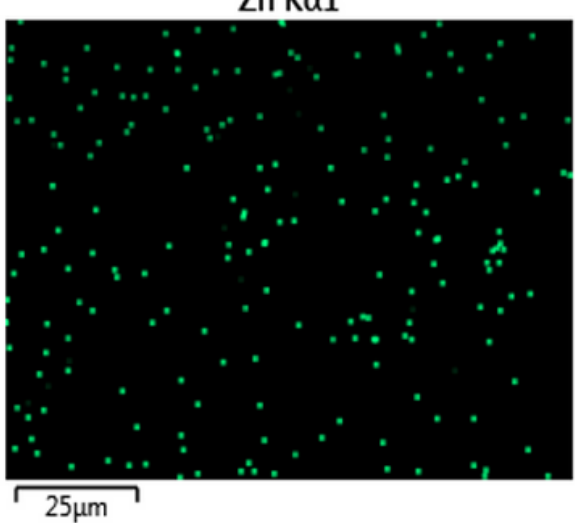

Figure 8

Energy Dispersive Microscopy (EDS) images for Spark Plasma Sintered Composite 


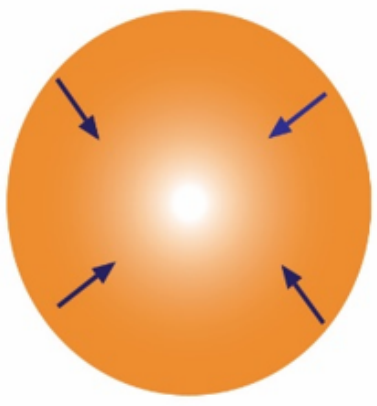

Conventional Sintering (Heat flow from outer surface)

Heat Flow Direction

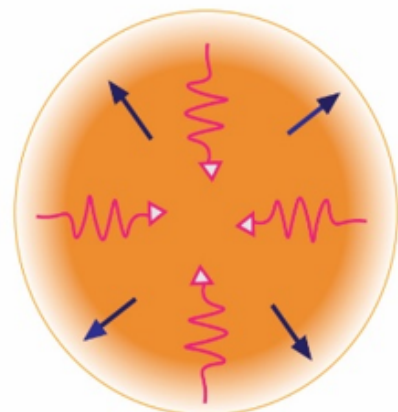

Microwave Sintering (Internal Heat Generation)

$\sim M \triangleright$ Microwaves Diection

$\rightarrow$ Heat Flow Direction

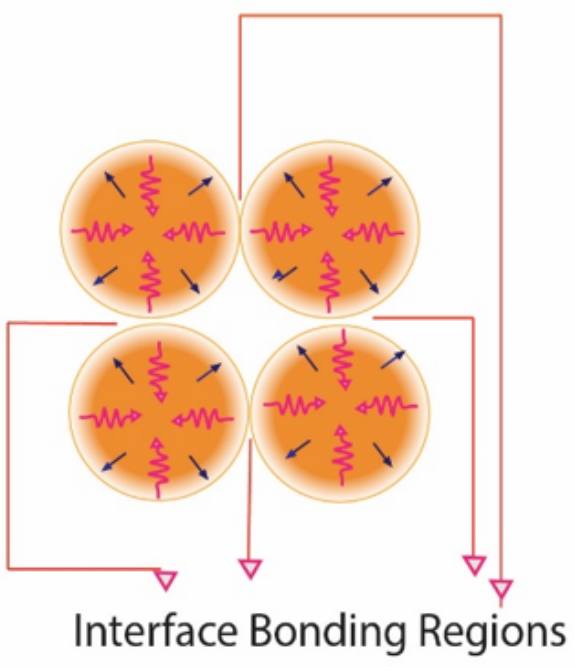

\section{Figure 9}

Schematic diagram for heat flow in Conventional sintering and Microwave sintering [22]

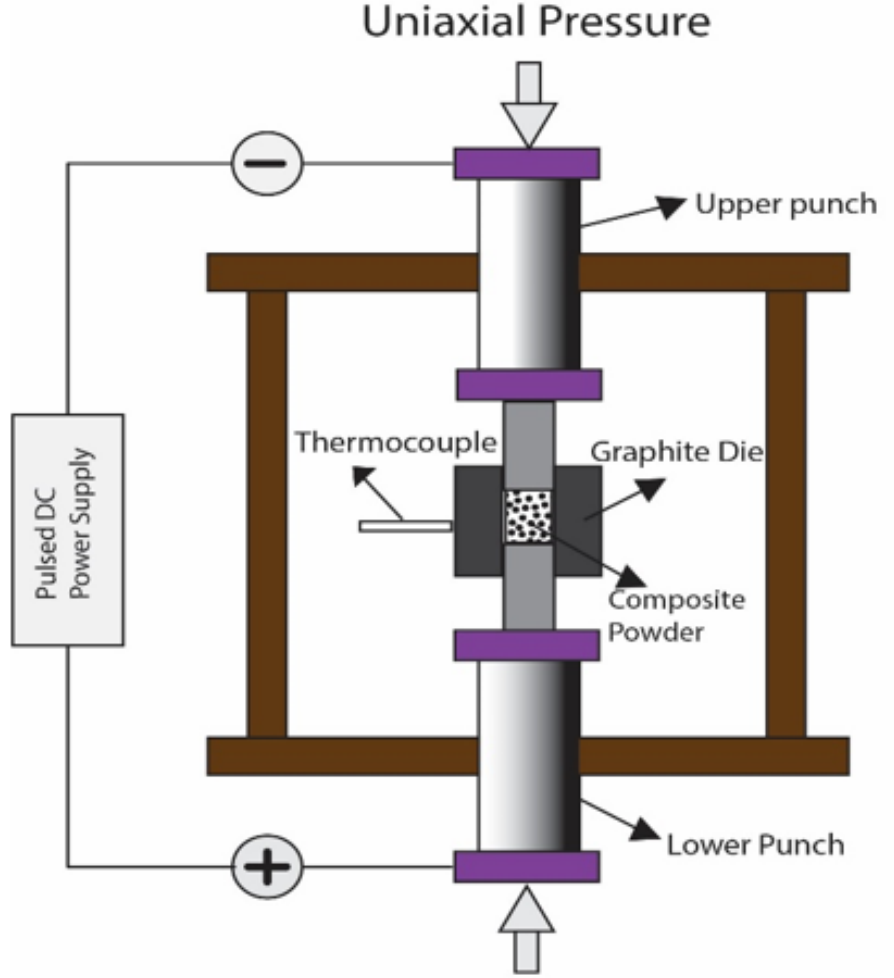

Uniaxial Pressure

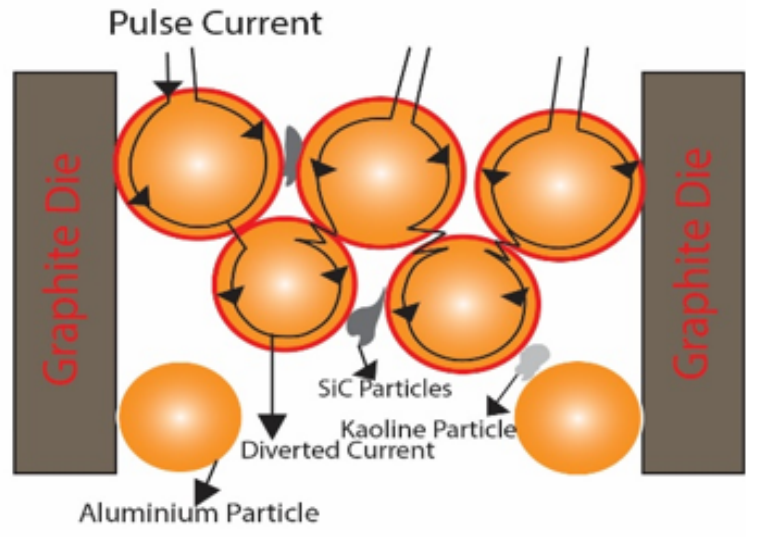

Surface High Temperature
Jouls Heating
W Discharge

( a ) 
Schematic diagram for (a) Spark Plasma Sintering process, (b) Heating in SPS process [22].

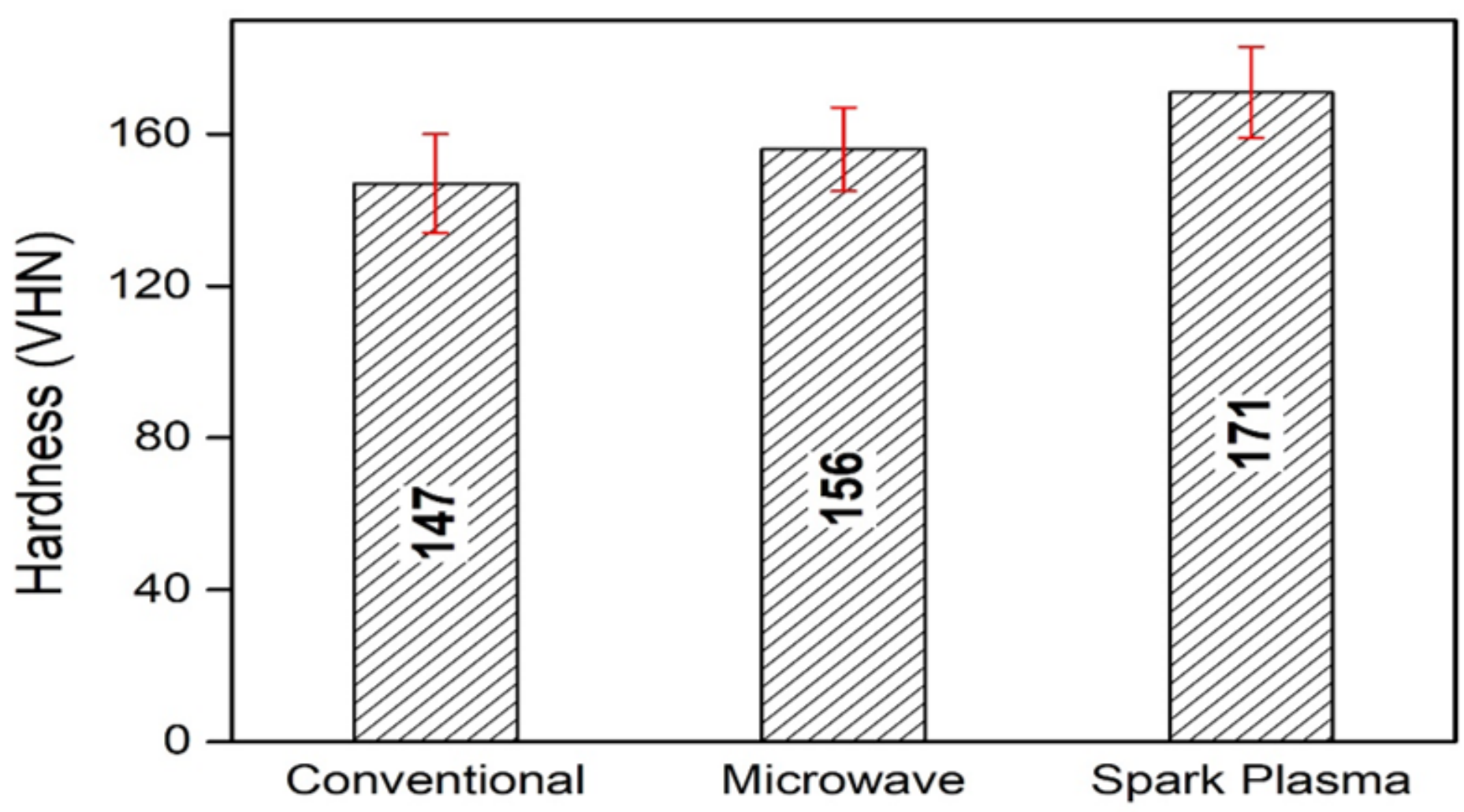

Figure 11

Variation in Hardness of HMMC fabricated through different sintering mechanisms 


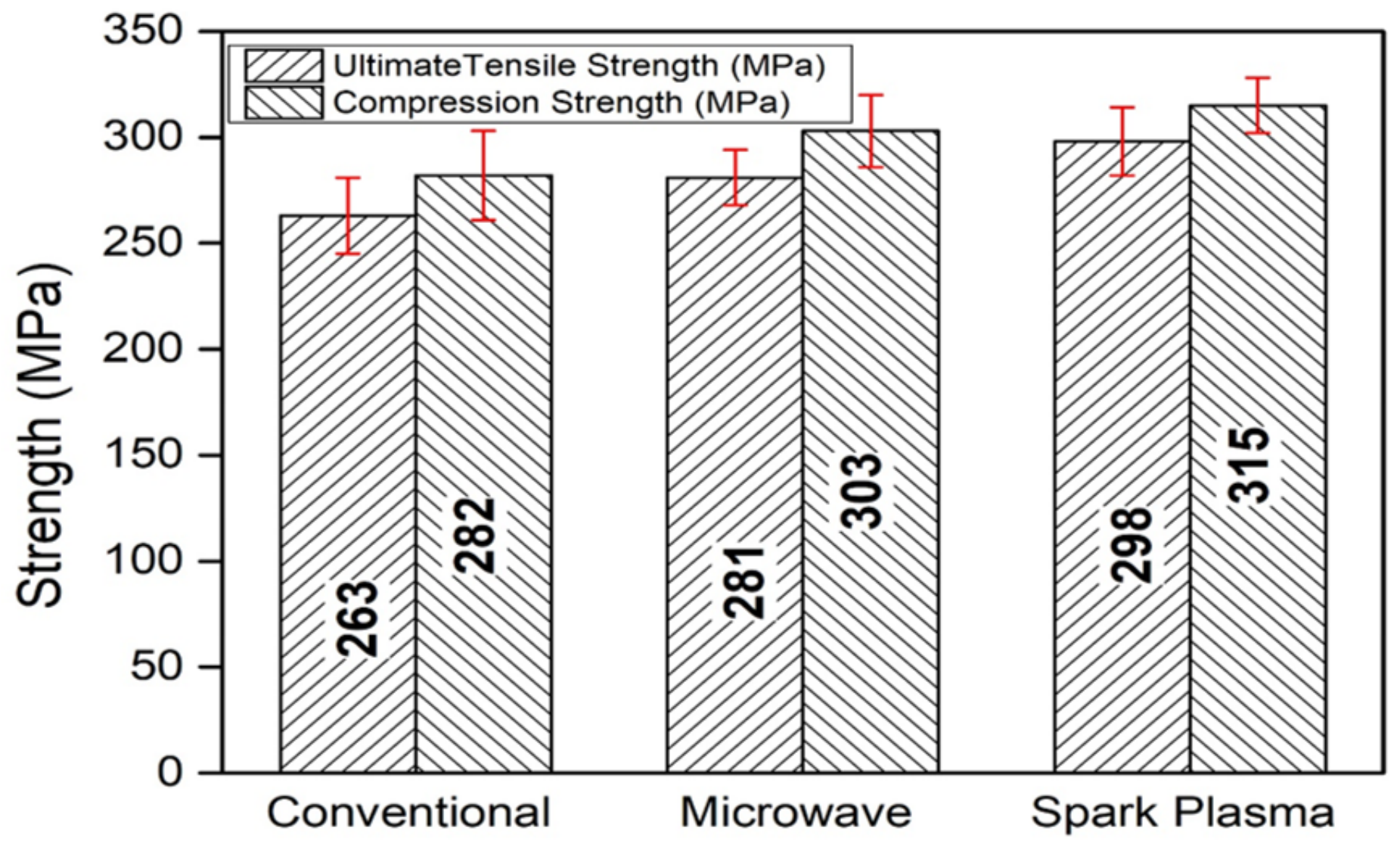

Figure 12

Variation in U.T.S and Compression strength of HMMC fabricated through different sintering mechanisms 


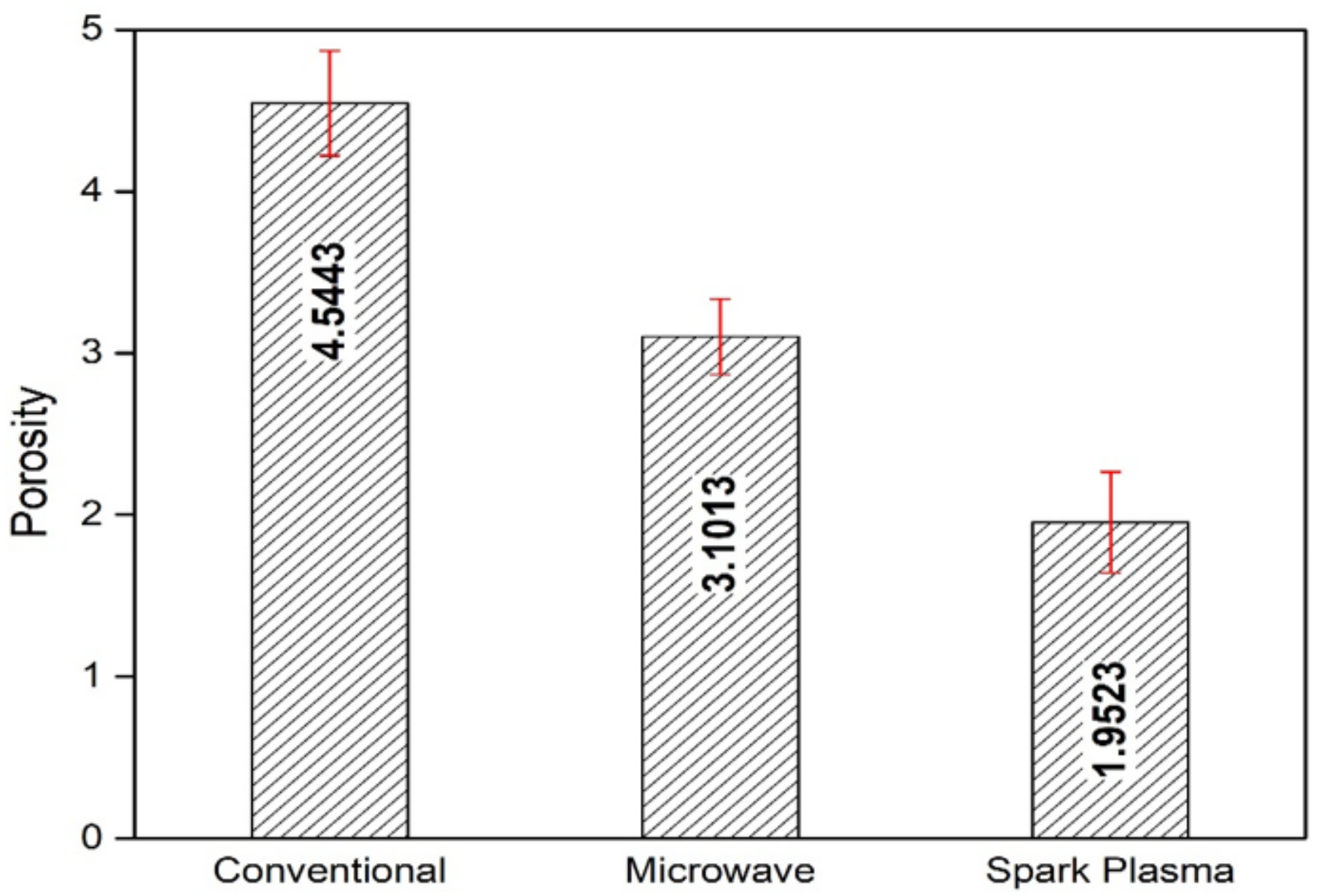

Figure 13

Variation in \% Porosity of HMMC fabricated through different sintering mechanisms 


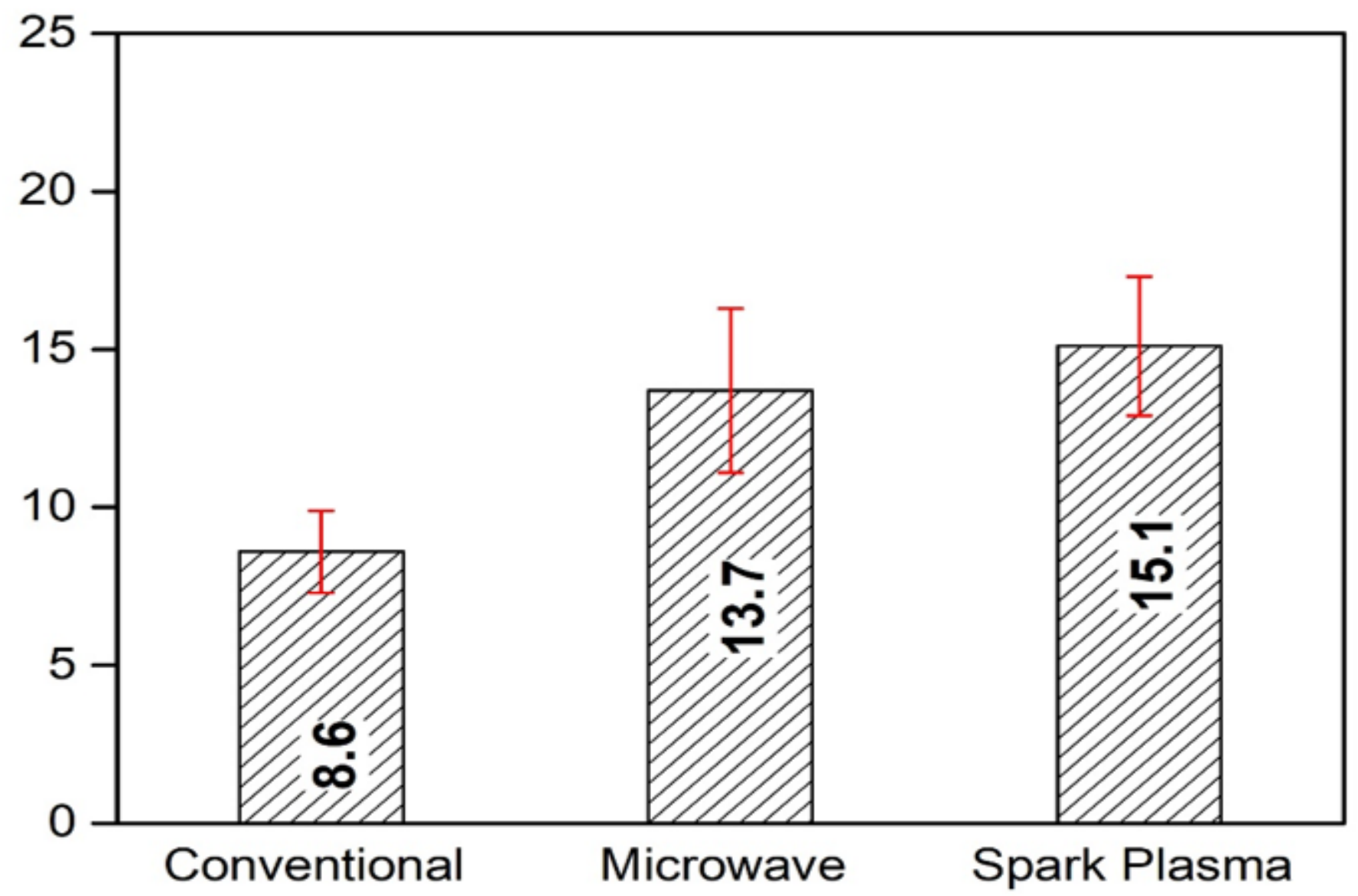

Figure 14

Variation of Impact energy of HMMC fabricated through different sintering mechanisms 

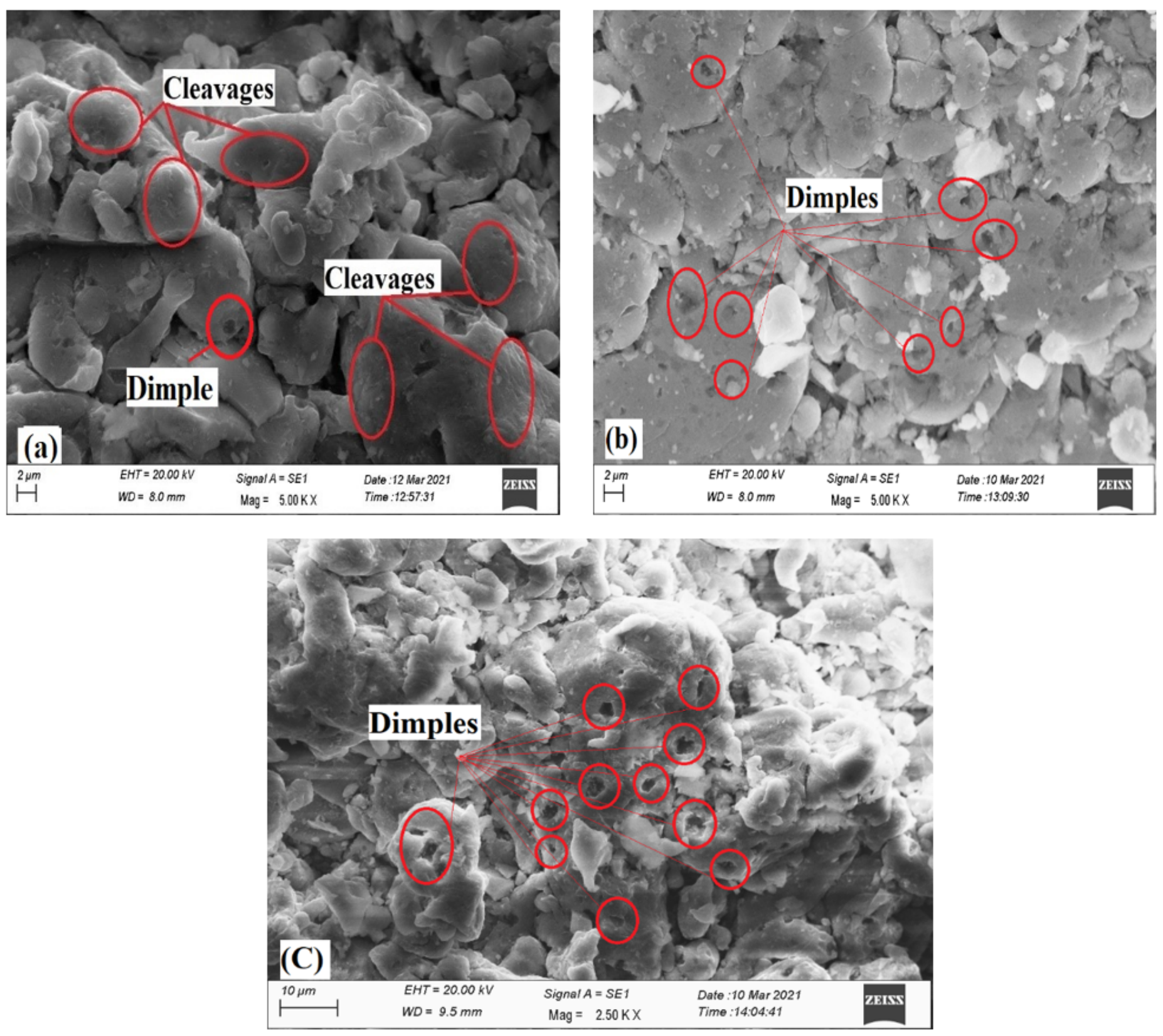

\section{Figure 15}

Fractured tensile Al-10\% SiC-4\% Kaoline HMMC fabricated through (a) Conventional Sintering, (b) Microwave Sintering and (c) Spark Plasma Sintering. 